\title{
All that glitters is not gold: Rosai-Dorfman as a single cerebellar necrotic lesion
}

\author{
Guilherme J. Agnoletto, ${ }^{1}$ Esther N Bit-Ivan, ${ }^{2}$ Ricardo A. Hanel, ${ }^{1}$ Eric Sauvageau ${ }^{1}$
}

${ }^{1}$ Cerebrovascular, Oncologic and Skull Base Neurosurgery, Lyerly Neurosurgery, Baptist Neurological Institute, Jacksonville, Florida, USA ${ }^{2}$ Neuro-pathology, Southeastern Pathology Associates at Baptist Medical Center, Jacksonville, Florida, USA

\section{Correspondence to} Dr Ricardo A. Hanel, rhanel@lyerlyneuro.com

Accepted 16 April 2019

\section{DESCRIPTION}

A 46-year-old man with a family history of renal cancer (father and grandfather), presented with a 5 -day complaint of headache, nausea and photophobia. Neurological exam was intact. CT revealed a single mass in the right cerebellar hemisphere compressing the fourth ventricle and brainstem, without hydrocephalus. MRI showed heterogeneously contrast enhancement with surrounding oedema and central areas of necrosis (figure 1).

CT chest, abdomen and pelvis were unrevealing for suspicious systemic lesion. Preoperative assessment was unremarkable with no metabolic or haematological abnormalities. The patient was electively taken to the operating room, under general anaesthesia placed in prone position, with the head slightly flexed, on a Mayfield clamp. A suboccipital craniotomy extended to the foramen magnum was performed; the tumour was exposed and found to have a soft consistency and to be extremely vascularised and haemorrhagic. Frozen section indicated primary central nervous system (CNS) lymphoma, and gross total resection was achieved.

Postoperative MRI revealed no residual lesion, haemorrhages or other complications (figure 2).

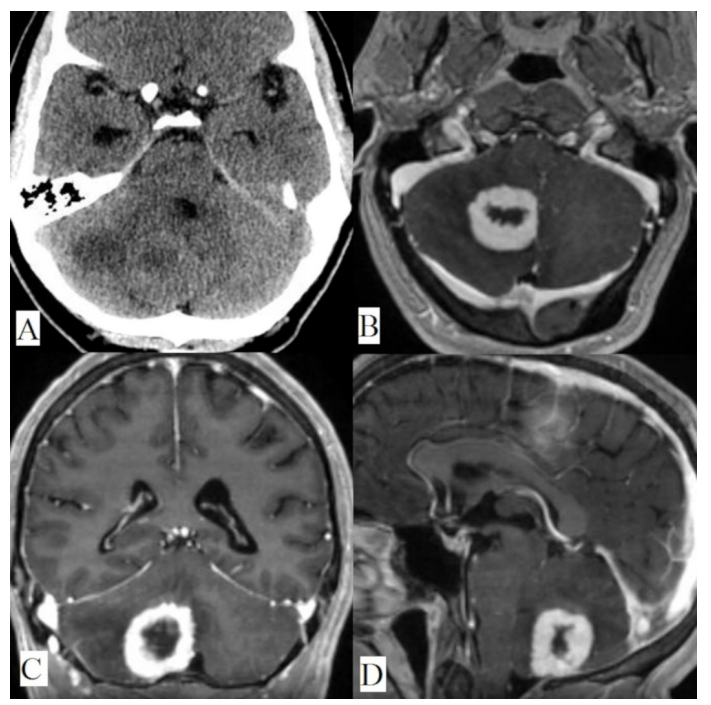

(C) BMJ Publishing Group Limited 2019. No commercial re-use. See rights and permissions. Published by BMJ.

\footnotetext{
To cite: Agnoletto GJ., Bit-Ivan EN, Hanel RA., et al. BMJ Case Rep 2019;12:e228483. doi:10.1136/bcr-2018228483
}

Figure 1 (A) Non-contrast CT showing spherical mass in the right cerebellar hemisphere with surrounding oedema and mass effect on the fourth ventricle. (A-C) Axial, coronal and sagittal cuts of a T1 sequence MRI with contrast revealing a $2.8 \mathrm{~cm}$ spherical thick-walled heterogeneously enhancing mass in the medial right cerebellar hemisphere with surrounding vasogenic oedema and central areas of internal non-enhancement/ necrosis, causing mass effect on the fourth ventricle.

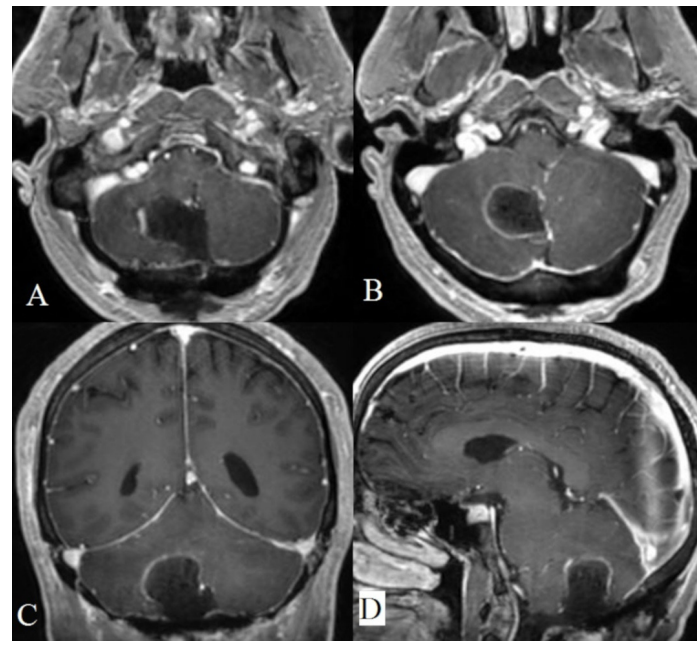

Figure 2 (A-D) Two axial, a coronal and a sagittal cut of a T1 sequence MRI with contrast postoperative, confirming gross total resection of the lesion.

Final pathology report astonished with a diagnosis of primary CNS Rosai-Dorfman disease (figure 3). In addition, the patient developed postoperative aseptic meningitis, which is extremely unusual for this disease, and was treated with corticosteroids. Since the disease is potentially curable with complete resection alone, the patient will keep follow-up without adjuvant treatment. ${ }^{1-3}$

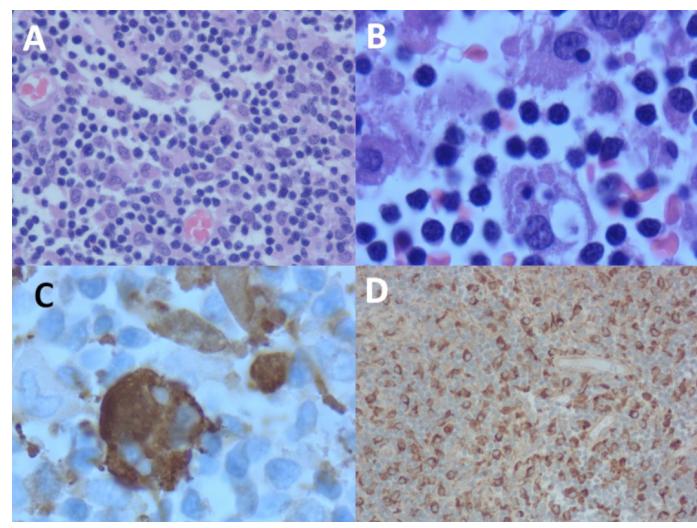

Figure 3 (A) H\&E stain shows a mixture of histiocytes and mature lymphocytes (40x). (B) Rare histiocytes have lymphocytes traversing their cytoplasm which is known as emperipolesis (100x). (C) The histiocytes are positive for S-100 by immunohistochemical stain $(100 x)$. The small, non-staining nuclei are lymphocytes traversing the cytoplasm. CD1a was negative. (D) The histiocytes are also positive for CD68 (20x). 
This is a very rare condition to present primarily in the CNS. Few cases have been reported in the literature and even fewer cases presenting as a single cerebellar lesion. ${ }^{1-3}$ Furthermore, all of them presented with usual imaging presentation for the disease, which is a homogeneous enhancing solid lesion on MRI, with dural relations, similar to a meningioma. ${ }^{1-3}$

This case had an extremely rare presentation of the disease, with a solitary lesion and atypical imaging. It showcases that

\section{Learning points}

- Although single contrast-enhancing cerebellar mass with central necrosis should suscite suspicious for metastasis, one should never shut their eyes to other possibilities.

- Due to its lymphocytic nature, Rosai-Dorfman can be confused with lymphoma or other lymphoid diseases, and freezing should not be taken for valid in deciding extent of resection or adjuvant treatment when suspicious is made.

- Once diagnosis is made, gross total resection is usually curative, and no further treatment is necessary. some clues can lead to completely different conclusions, thus 'all that glitters is not gold'.

Contributors GJA was responsible for study concept and design. GJA and ENB-I contributed to acquisition of data. All the authors were responsible for the analysis and interpretation of data. All authors contributed to drafting of the manuscript. RAH and ES contributed to critical revision of the manuscript for important intellectual content. All the authors were responsible for administrative, technical and material support. RAH and ES contributed to study supervision.

Funding The authors have not declared a specific grant for this research from any funding agency in the public, commercial or not-for-profit sectors.

Competing interests None declared.

Patient consent for publication Obtained.

Provenance and peer review Not commissioned; externally peer reviewed.

\section{REFERENCES}

1 Beros V, Houra K, Rotim K, et al. Isolated cerebellar intraparenchymal Rosai-Dorfman disease-case report and review of literature. Br J Neurosurg 2011;25:292-6.

2 Luo Z, Zhang Y, Zhao P, et al. Characteristics of Rosai-Dorfman Disease Primarily Involved in the Central Nervous System: 3 Case Reports and Review of Literature. World Neurosurg 2017;97:58-63.

3 Sandoval-Sus JD, Sandoval-Leon AC, Chapman JR, et al. Rosai-Dorfman disease of the central nervous system: report of 6 cases and review of the literature. Medicine 2014;93:165-75.

Copyright 2019 BMJ Publishing Group. All rights reserved. For permission to reuse any of this content visit

https://www.bmj.com/company/products-services/rights-and-licensing/permissions/

BMJ Case Report Fellows may re-use this article for personal use and teaching without any further permission.

Become a Fellow of BMJ Case Reports today and you can:

- Submit as many cases as you like

- Enjoy fast sympathetic peer review and rapid publication of accepted articles

- Access all the published articles

Re-use any of the published material for personal use and teaching without further permission

For information on Institutional Fellowships contact consortiasales@bmjgroup.com

Visit casereports.bmj.com for more articles like this and to become a Fellow 